\title{
Radiation dose and repeatability of aortic valve measurement by multidetector row computed tomography to assess eligibility for transcatheter aortic valve implantation
}

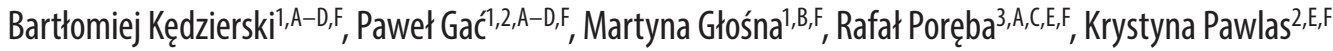 \\ ${ }^{1}$ Centre for Diagnostic Imaging, $4^{\text {th }}$ Military Hospital, Wrocław, Poland \\ 2 Department of Hygiene, Wroclaw Medical University, Poland \\ ${ }^{3}$ Department of Internal Medicine, Occupational Diseases and Hypertension, Wroclaw Medical University, Poland \\ A - research concept and design; B - collection and/or assembly of data; C - data analysis and interpretation; \\ $D$ - writing the article; $E$ - critical revision of the article; $F$ - final approval of the article
}

Address for correspondence

Paweł Gać

E-mail:pawelgac@interia.pl

Funding sources

None declared

Conflict of interest

None declared

Received on September 23, 2019

Reviewed on May 17, 2020

Accepted on June 7, 2020

Published online on August 27, 2020

Cite as

Kędzierski B, Gać P, Głośna M, Poręba R, Pawlas K.

Radiation dose and repeatability of aortic valve measurement

by multidetector row computed tomography to assess

eligibility for transcatheter aortic valve implantation.

Adv Clin Exp Med. 2020;29(8):983-992.

doi:10.17219/acem/123624

DOI

10.17219/acem/123624

Copyright

Copyright by Author(s)

This is an article distributed under the terms of the

Creative Commons Attribution 3.0 Unported (CC BY 3.0)

(https://creativecommons.org/licenses/by/3.0/)

\section{Abstract}

Background. Aortic valve stenosis is among the most common valvular defects in developed countries. In the assessment of eligibility for transcatheter aortic valve implantation (TAVI), multidetector row computed tomography $(\mathrm{MDCT})$ is performed to determine the precise dimensions of the aortic valve, the topography of the aortic ostium and the ability to use various arterial access routes.

Objectives. To evaluate the relationships between the radiation dose and the repeatability of measurements of dimensions of the aortic valve in MDCT performed before TAVI.

Material and methods. The study involved a group of 60 consecutive patients undergoing MDCT before TAVI. The radiation dose was expressed as computed tomography dose index volume (CTDlvol) and dose length product (DLP). The coefficient of variation (CV) of each measurement was defined as the standard deviation (SD) of the measurements/mean measurement $\times 100 \%$, based on the measurements performed independently by 2 radiologists.

Results. A statistically significant negative linear correlation was observed between the DLP value of the MDCT before TAVI, and the CV of the measurement of the minimum dimension of the aortic annulus $(r=-0.25 ; p<0.05)$. Lower DLP doses of the MDCT before TAVI constitute an independent factor associated with a higher $\mathrm{CV}$ for the measurement of the minimum dimension of the aortic annulus.

Conclusions. It is proposed that tests using lower radiation doses should be followed by an assessment of the degree of repeatability of the aortic valve sizing.

Key words: aortic valve, coefficient of variation, radiation dose, TAVI, repeatability of measurement 


\section{Introduction}

Aortic valve stenosis is among the most common valvular defects in developed countries. ${ }^{1}$ The treatment of choice in patients with severe aortic stenosis is implantation of a prosthetic aortic valve. ${ }^{2}$ For a large group of elderly patients with a significant burden of comorbidities, the risk of classic cardiosurgical aortic valve replacement is too high. The solution in these patients is transcutaneous (transcatheter) aortic valve implantation (TAVI). ${ }^{3,4}$ In the assessment of eligibility for TAVI, standard imaging tests are performed to determine the precise dimensions of the aortic valve, the topography of the aortic ostium and the ability to use various arterial access routes. Currently, the standard examination is multidetector row computed tomography (MDCT) of the heart and large vessels. ${ }^{5,6}$

Computed tomography (CT) scans expose patients to ionizing radiation. Due to a direct effect on the double DNA helix, and - as a result of water radiolysis - the formation of free oxygen radicals interacting with the DNA (i.e., an indirect effect), ionizing radiation causes modifications in the cellular genetic material that may be associated with deterministic and stochastic consequences. ${ }^{7}$ Following the principles established by the International Commission on Radiological Protection (ICRP), no procedure involving radiation exposure should be performed unless it provides sufficient benefits to the exposed patients or society, outweighing the radiation-induced damage to the health related to this procedure. If the benefit-toharm balance associated with procedures using ionizing radiation is positive, it is necessary to find a way to optimize the radiation dose. ${ }^{8}$ Following the rules of radiological protection and the ALARA principle (as low as reasonably achievable), the ionizing radiation dose should preferably be reduced during those procedures using this form of radiation. An adequate level of quality for the diagnostic images should be maintained; however, if a minor loss of quality allows the radiation dose to be reduced, it is justified., ${ }^{9} 10$

Minimizing the radiation for those studies involving high doses, such as CT of the heart and large vessels during the assessment for TAVI, is particularly important, as there is a direct relationship between the radiation dose and the risk of stochastic consequences from the ionizing radiation. ${ }^{11}$ However, the costs associated with reduced exposure due to the use of lower exposure doses increase disproportionately to the degree of effective dose reduction. ${ }^{12}$ Therefore, it is not socially justified or economically profitable to avoid every small risk. Therefore, efforts should be focused on optimizing high and moderate doses.

It may be interesting to determine whether or not the attempt to decrease the dose used in MDCT studies during the assessment of eligibility for TAVI would result in an overly significant reduction in scan quality, in this case defined primarily as reduced repeatability of aortic valve sizing. To achieve this goal, the hypothesis regarding the relationship between the ionizing radiation dose in standard MDCT examinations and the repeatability of aortic valve sizing needs to be verified.

\section{Study purpose}

The aim of the study was to assess the relationships between the ionizing radiation dose and the repeatability of the aortic dimension measurements using MDCT, as part of a standard assessment of eligibility for TAVI.

\section{Material and methods}

\section{Study group}

The study involved a group of 60 consecutive patients, who received MDCT of the heart and large vessels as part of the eligibility assessment for TAVI in the years 20122016. The mean age of the subjects was $79.60 \pm 9.17$ years, and mean body mass index (BMI) was $27.85 \pm 3.99 \mathrm{~kg} / \mathrm{m}^{2}$. In the study, $63.3 \%$ of the subjects were males and $36.7 \%$ were females. Only $25.0 \%$ of the subjects had normal body weight, $51.7 \%$ were overweight and $23.3 \%$ were obese. The clinical characteristics of the study group are presented in Table 1.

\section{Study design}

The study was part of the project "Possible optimization of ionizing radiation dose in computed tomography studies during the eligibility assessment for transcatheter aortic valve implantation". The study protocol was approved by the local bioethics committee (approval No. KB 198/2018). Clinical data of all the subjects were collected, and all the patients received a MDCT examination of the heart and large vessels.

\section{Basic anthropometric parameters}

The BMI was calculated using the following formula: $\mathrm{BMI}=$ body weight $[\mathrm{kg}] /$ height $[\mathrm{m}] \wedge 2$. Body surface area (BSA) was derived on the basis of the DuBois formula: $\mathrm{BSA}=0.007184 \times$ body weight $[\mathrm{kg}]^{\wedge} 0.425 \times$ height $[\mathrm{cm}] \wedge 0.725$. Normal body weight was defined as BMI $<25 \mathrm{~kg} / \mathrm{m}^{2}$, overweight was defined as BMI $25-29.9 \mathrm{~kg} / \mathrm{m}^{2}$ and obesity was defined as BMI $\geq 30 \mathrm{~kg} / \mathrm{m}^{2}$.

\section{MDCT studies}

All the MDCT examinations of the heart and large vessels during the eligibility assessment for TAVI were performed using a SOMATOM Definition Dual-Source CT scanner (Siemens Healthcare, Kemnath, Germany), following a standardized angiography protocol. The study protocol included a topogram, pre-monitoring and monitoring 
Table 1. Clinical characteristics of the study group $(n=60)$

\begin{tabular}{|c|c|c|c|c|c|}
\hline Variable & $\mathrm{x}$ & $\mathrm{Me}$ & Min & Max & SD \\
\hline Age [years] & 79.60 & 82.00 & 44.00 & 95.00 & 9.17 \\
\hline Height $[\mathrm{cm}]$ & 169.55 & 170.00 & 148.00 & 186.00 & 8.08 \\
\hline Body mass [kg] & 80.10 & 80.00 & 52.00 & 112.00 & 12.84 \\
\hline BMI $\left[\mathrm{kg} / \mathrm{m}^{2}\right]$ & 27.85 & 28.32 & 19.27 & 37.38 & 3.99 \\
\hline $\mathrm{BSA}\left[\mathrm{m}^{2}\right]$ & 1.91 & 1.93 & 1.50 & 2.30 & 0.17 \\
\hline $\begin{array}{l}\text { Gender, n (\%) } \\
\text { men } \\
\text { women }\end{array}$ & & & $\begin{array}{l}38(63.3) \\
22(36.7)\end{array}$ & & \\
\hline $\begin{array}{l}\text { Body mass, } n(\%) \\
\text { normal body mass } \\
\text { overweight } \\
\text { obesity }\end{array}$ & & & $\begin{array}{l}15(25.0) \\
31(51.7) \\
14(23.3)\end{array}$ & & \\
\hline
\end{tabular}

$\mathrm{BMI}$ - body mass index; BSA - body surface area; Max - maximum value; Min - minimum value; $\mathrm{n}$ - number of patients; SD - standard deviation; $X$ - arithmetic mean.

at the level of tracheal bifurcation, with acquisition triggered by the required contrast enhancement of the region of interest (ROI) in the ascending aorta, an electrocardiography (ECG)-gated thoracic arterial phase angiography, and a non-ECG-gated angiography of the abdominal and pelvic arteries. The basic technical parameters of the angiographic phases included: craniocaudal direction of image acquisition, spiral method of image acquisition, study scope from the pulmonary apexes to half the length of the femoral shafts, layer collimation of $0.6 \mathrm{~mm}$, exposure kilovoltage of 120 units, and variable mAs values. The examination involved an intravenous administration of a contrast medium at a volume determined by the patient's body weight. Between $90 \mathrm{~mL}$ and $120 \mathrm{~mL}$ of iodinebased, non-ionic contrast medium was administered using an automatic syringe into the veins in the cubital fossa with infusion rate of $4.0 \mathrm{~mL} / \mathrm{s}$. Reconstructions were performed in axial orientations, in layers of $3.0 \mathrm{~mm}$ and $0.75 \mathrm{~mm}$, and secondary multi-planar reconstructions (MPRs) were obtained in the coronal and sagittal planes, using maximum intensity projection (MIP) and volume rendering technique (VRT) algorithms.

\section{lonizing radiation dose}

The ionizing radiation dose was determined by recording automated measurements performed using CT. The radiation dose was expressed as computed tomography dose index volume (CTDIvol) and dose length product (DLP) for the thoracic arterial phase MDCT.

\section{Aortic valve assessment}

The CT scans of the heart and large vessels were analyzed in terms of assessing the aortic valve and aortic root sizing, topography of the aortic ostium and the possibility to use various arterial access routes during the TAVI procedure. The tests were evaluated following the recommendations of the Society of Cardiovascular Computed
Tomography expert consensus document on CT imaging before TAVI/transcatheter aortic valve replacement (TAVR). ${ }^{6}$ For the purpose of this project, the tests were assessed independently by 2 radiologists with 7 and 10 years of experience in the assessment of CT heart scans, respectively. The assessment involved the following parameters of the aortic valve and root: type of valve (number of leaflets); maximum, minimum and mean dimension of the aortic annulus; maximum, minimum and mean dimension of the aortic root and its height; and distance between the left and the right coronary artery ostia and the aortic annulus (Fig. 1A-F). All the measurements were expressed in millimeters to an accuracy of $0.1 \mathrm{~mm}$.

\section{Assessment of the repeatability of measurements}

The analysis of repeatability of the measurements involved the following quantitative variables, calculated on the basis of the measurement of the aortic valve and aortic root parameters, performed independently by 2 radiologists experienced in the evaluation of the cardiovascular system: measurement mean (X), standard deviation (SD), absolute difference (AD), relative difference (RD), and coefficient of measurement variation $(\mathrm{CV})$. The following mathematical formulas were used to calculate the above characteristics of measurement repeatability: $\mathrm{AD}=\mid$ measurement 1 - measurement $2 \mid$; $\mathrm{RD}=\mathrm{AD}$ of the measurement/X of the measurement; $\mathrm{CV}=\mathrm{SD}$ of the measurement/X of the measurement $\times 100 \%$. Absolute difference was expressed in $\mathrm{mm}$, RD had no unit, and CV was expressed as percentage.

\section{Subgroups}

In the comparative analyses of the studied group of MDCT examinations conducted to assess eligibility for TAVI, the following subgroups were distinguished, based on the median CTDIvol and DLP values for 

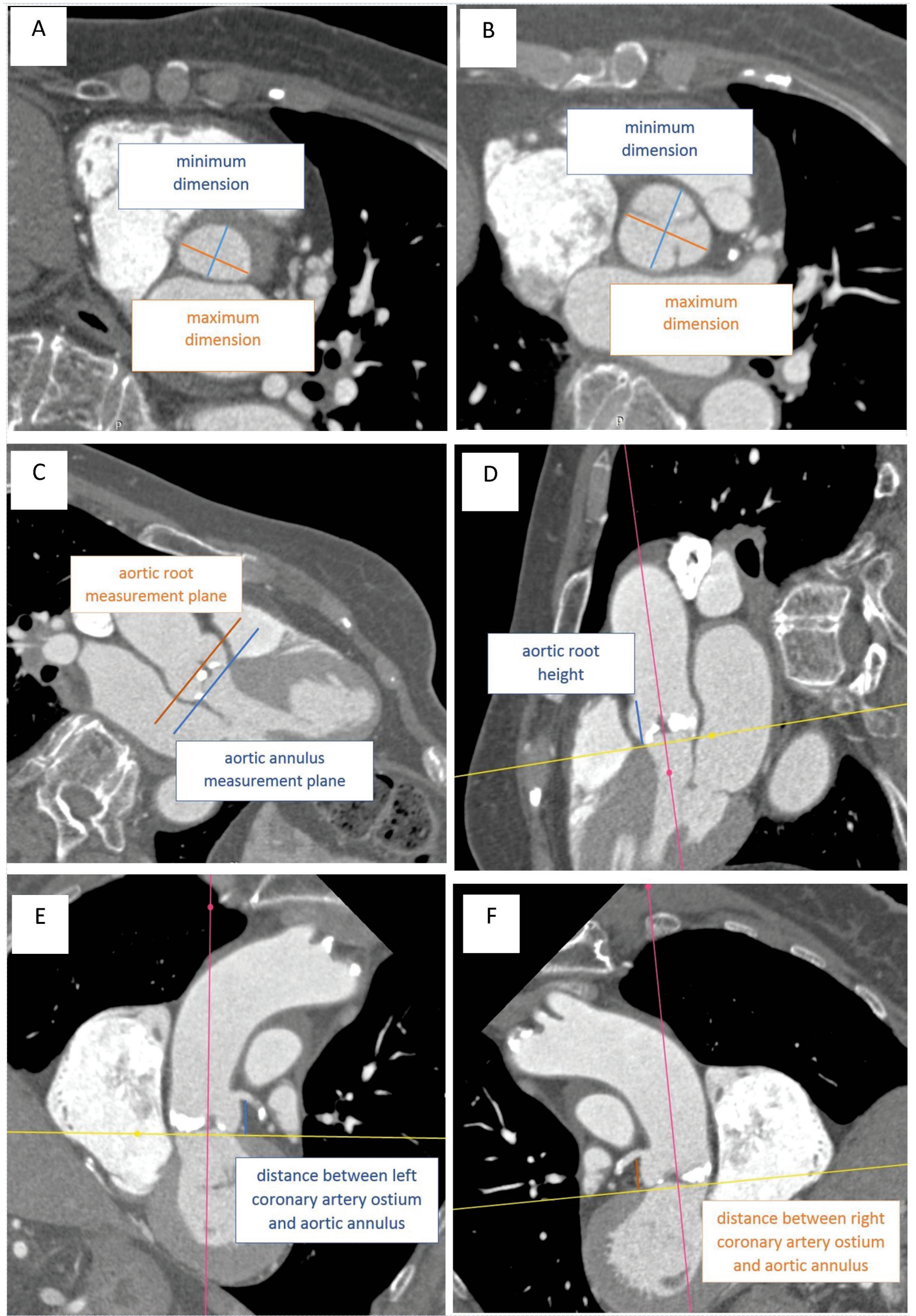

Fig. 1. Computed tomography aortic valve measurements: A) maximum and minimum dimension of the aortic annulus (mean dimension of the aortic annulus $=$ (maximum dimension of the aortic annulus + minimum dimension of the aortic annulus)/2); B) maximum and minimum dimension of the aortic root (mean dimension of the aortic root = (maximum dimension of the aortic root + minimum dimension of the aortic root)/2); C) aortic annulus and aortic root measurement planes; D) height of the aortic root; $\mathrm{E}$ ) distance between the left coronary artery ostium and the aortic annulus; F) distance between the right coronary artery ostium and the aortic annulus 
the thoracic arterial phase of the MDCT. Based on the median CTDIvol (43.92 mGy), a low CTDIvol (CTDIvol $<$ Me, $\mathrm{n}=30$ ) and a high CTDIvol (CTDIvol $\geq M e, \mathrm{n}=30$ ) subgroup were identified. Considering the median DLP (1143.00 mGy), a low DLP (DLP < Me, $\mathrm{n}=29)$ and a high DLP (DLP $\geq M e, n=31)$ subgroup were identified.

\section{Statistical analysis}

Statistical analyses were conducted using Dell Statistica v. 13 software (Dell Inc., Austin, USA). The quantitative variables were characterized with arithmetic means, medians, maximum and minimum values, and SD. The distribution of the variables was verified using the ShapiroWilk W test. Due to absence of normal distribution in comparative analyses, the Mann-Whitney U test was used. The results for qualitative variables were characterized by absolute values and percentages. In order to determine the relationships between the analyzed variables, both correlation analysis (2 variables) and multiple regression analyses (more than 2 variables) were conducted. Those results with $\mathrm{p}<0.05$ were considered statistically significant.

\section{Results}

The mean CTDIvol and DLP values for the thoracic arterial phase of the MDCT during the eligibility assessment for TAVI were $48.71 \pm 20.33 \mathrm{mGy}$ and $1319.98 \pm 613.58$ mGycm, respectively. In the studied population, $93.3 \%$ of the patients had a tricuspid aortic valve, $5 \%$ had a bicuspid aortic valve and $1.7 \%$ had a quadricuspid aortic valve. The mean dimensions of the aortic annulus and the aortic root were $24.44 \pm 2.50 \mathrm{~mm}$ and $32.20 \pm 3.95 \mathrm{~mm}$, respectively. The complete results of aortic valve assessment in the MDCT tests for TAVI in the studied group of patients are presented in Table 2 .

The analysis of repeatability of aortic valve measurements in the MDCT tests assessing the eligibility for TAVI in the studied subjects showed the greatest absolute measurement difference in the distance between the left coronary artery ostium and the aortic annulus $(1.77 \pm 0.96 \mathrm{~mm})$, whereas the smallest absolute measurement difference was found in the mean dimension of the aortic annulus $(0.97 \pm 0.60 \mathrm{~mm})$. The greatest relative measurement difference and the highest CV was observed in the distance between the left coronary artery ostium and aortic annulus $(0.13 \pm 0.07 \%$ and $9.24 \pm 5.17 \%$, respectively). The smallest relative measurement difference and the smallest $\mathrm{CV}$ were found in the mean dimension of the aortic root $(0.03 \pm 0.02 \%$ and $2.39 \pm 1.72 \%$, respectively). The results of the analysis of aortic valve measurement repeatability in the MDCT tests for TAVI in the studied group of patients are presented in Table 3.

A comparative analysis did not reveal any statistically significant differences in the mean values of the parameters characterizing the repeatability of individual aortic valvular measurements between the groups identified based on the median CTDIvol in the thoracic arterial phase of the MDCT examination used to assess the eligibility for TAVI (Table 4).

Table 2. Aortic valve assessment in MDCT scans evaluating the eligibility for TAVI in the study group $(n=60)$

\begin{tabular}{|c|c|c|c|c|c|}
\hline Variable & \multicolumn{2}{|c|}{$\mathrm{n}$} & \multicolumn{3}{|c|}{$\%$} \\
\hline $\begin{array}{l}\text { Number of aortic valve leaflets } \\
2 \\
3 \\
4\end{array}$ & \multicolumn{2}{|c|}{$\begin{array}{c}3 \\
56 \\
1\end{array}$} & \multicolumn{3}{|c|}{$\begin{array}{c}5.0 \\
93.3 \\
1.7\end{array}$} \\
\hline Statistical variable & $x$ & $\mathrm{Me}$ & Min & $\operatorname{Max}$ & SD \\
\hline $\begin{array}{l}\text { Aortic annulus } \\
\text { maximum dimension }[\mathrm{mm}] \\
\text { minimum dimension }[\mathrm{mm}] \\
\text { mean dimension }[\mathrm{mm}]\end{array}$ & $\begin{array}{l}27.04 \\
21.84 \\
24.44\end{array}$ & $\begin{array}{l}27.00 \\
21.50 \\
23.88\end{array}$ & $\begin{array}{l}22.50 \\
17.50 \\
20.00\end{array}$ & $\begin{array}{l}35.50 \\
31.00 \\
31.50\end{array}$ & $\begin{array}{l}3.05 \\
2.83 \\
2.50\end{array}$ \\
\hline $\begin{array}{l}\text { Aortic root } \\
\text { maximum dimension }[\mathrm{mm}] \\
\text { minimum dimension }[\mathrm{mm}] \\
\text { mean dimension }[\mathrm{mm}] \\
\text { height }[\mathrm{mm}]\end{array}$ & $\begin{array}{l}33.95 \\
30.44 \\
32.20 \\
21.23\end{array}$ & $\begin{array}{l}33.75 \\
30.00 \\
31.75 \\
20.75\end{array}$ & $\begin{array}{l}27.50 \\
18.00 \\
24.25 \\
17.00\end{array}$ & $\begin{array}{l}45.00 \\
44.50 \\
44.75 \\
29.00\end{array}$ & $\begin{array}{l}4.16 \\
4.33 \\
3.95 \\
2.71\end{array}$ \\
\hline $\begin{array}{l}\text { Distance between a coronary arte } \\
\text { and the aortic annulus } \\
\text { left coronary artery [mm] } \\
\text { right coronary artery [mm] }\end{array}$ & $\begin{array}{l}13.78 \\
15.06\end{array}$ & $\begin{array}{l}14.00 \\
15.00\end{array}$ & $\begin{array}{c}8.25 \\
10.50\end{array}$ & $\begin{array}{l}18.50 \\
20.50\end{array}$ & $\begin{array}{l}2.47 \\
2.51\end{array}$ \\
\hline $\begin{array}{l}\text { Radiation dose } \\
\text { CTDIvol [mGy] } \\
\text { DLP [mGycm] }\end{array}$ & $\begin{array}{c}48.71 \\
1319.98\end{array}$ & $\begin{array}{c}43.92 \\
1143.00\end{array}$ & $\begin{array}{c}24.60 \\
420.00\end{array}$ & $\begin{array}{c}99.14 \\
2887.00\end{array}$ & $\begin{array}{c}20.33 \\
613.58\end{array}$ \\
\hline
\end{tabular}

Aortic valve dimensions and distances: mean values of measurements conducted by 2 researchers; CTDlvol - computed tomography dose index volume; DLP - dose length product; Max - maximum value; Min - minimum value; $\mathrm{n}$ - number of patients; SD - standard deviation; $\mathrm{X}$ - arithmetic mean; TAVI - transcatheter aortic valve implantation; MDCT - multidetector row computed tomography. 
Table 3. Analysis of repeatability of aortic valve measurements in MDCT scans evaluating the eligibility for TAVI in the study group ( $\mathrm{n}=60$ ).

\begin{tabular}{|c|c|c|c|c|c|c|c|}
\hline Variable & $\begin{array}{c}\text { Measurement } \\
1 \\
{[\mathrm{~mm}]}\end{array}$ & $\begin{array}{c}\text { Measurement } \\
2 \\
{[\mathrm{~mm}]}\end{array}$ & $\begin{array}{c}\text { Measurement } \\
\mathrm{X} \\
{[\mathrm{mm}]}\end{array}$ & $\begin{array}{c}\text { Measurement } \\
\text { SD } \\
{[\mathrm{mm}]}\end{array}$ & $\begin{array}{c}\text { Measurement } \\
\text { AD } \\
{[\mathrm{mm}]}\end{array}$ & $\begin{array}{l}\text { Measurement } \\
\text { RD }\end{array}$ & $\begin{array}{c}\text { Measurement } \\
\text { CV } \\
{[\%]}\end{array}$ \\
\hline \multicolumn{8}{|c|}{ Aortic annulus } \\
\hline Maximum dimension & $26.72 \pm 3.11$ & $27.37 \pm 3.15$ & $27.04 \pm 3.05$ & $0.95 \pm 0.53$ & $1.35 \pm 0.76$ & $0.05 \pm 0.03$ & $3.58 \pm 2.12$ \\
\hline Minimum dimension & $21.60 \pm 2.78$ & $22.08 \pm 3.05$ & $21.84 \pm 2.83$ & $0.84 \pm 0.63$ & $1.18 \pm 0.89$ & $0.05 \pm 0.04$ & $3.83 \pm 2.92$ \\
\hline Mean dimension & $24.16 \pm 2.57$ & $24.73 \pm 2.53$ & $24.44 \pm 2.50$ & $0.68 \pm 0.42$ & $0.97 \pm 0.60$ & $0.04 \pm 0.02$ & $2.81 \pm 1.74$ \\
\hline \multicolumn{8}{|c|}{ Aortic root } \\
\hline Maximum dimension & $33.48 \pm 4.18$ & $34.42 \pm 4.28$ & $33.95 \pm 4.16$ & $1.01 \pm 0.66$ & $1.43 \pm 0.93$ & $0.04 \pm 0.03$ & $3.03 \pm 2.00$ \\
\hline Minimum dimension & $30.45 \pm 4.35$ & $30.43 \pm 4.46$ & $30.44 \pm 4.33$ & $0.93 \pm 0.73$ & $1.32 \pm 1.03$ & $0.05 \pm 0.04$ & $3.20 \pm 2.59$ \\
\hline Mean dimension & $31.97 \pm 3.98$ & $32.43 \pm 4.01$ & $32.20 \pm 3.95$ & $0.74 \pm 0.49$ & $1.04 \pm 0.69$ & $0.03 \pm 0.02$ & $2.39 \pm 1.72$ \\
\hline Height & $21.87 \pm 2.80$ & $20.60 \pm 2.84$ & $21.23 \pm 2.71$ & $1.24 \pm 0.71$ & $1.75 \pm 1.01$ & $0.08 \pm 0.05$ & $5.87 \pm 3.34$ \\
\hline Left coronary artery & $14.43 \pm 2.73$ & $13.12 \pm 2.44$ & $13.78 \pm 2.47$ & $1.25 \pm 0.68$ & $1.77 \pm 0.96$ & $0.13 \pm 0.07$ & $9.24 \pm 5.17$ \\
\hline Right coronary artery & $14.47 \pm 2.58$ & $15.65 \pm 2.73$ & $15.06 \pm 2.51$ & $1.24 \pm 0.79$ & $1.75 \pm 1.11$ & $0.12 \pm 0.07$ & $8.29 \pm 5.22$ \\
\hline
\end{tabular}

Values are expressed as mean \pm standard deviation (SD); AD - absolute difference; CV - coefficient of variation; RD - relative difference; X - arithmetic mean; TAVI - transcatheter aortic valve implantation; MDCT - multidetector row computed tomography.

Table 4. Analysis of repeatability of aortic valve measurements in MDCT scans evaluating the eligibility for TAVI in subgroups identified based on median CTDIvol

\begin{tabular}{|c|c|c|c|c|}
\hline & Variable & $\begin{array}{l}\text { Low CTDIvol (CTDIvol < Me, } \\
\qquad \mathrm{n}=30)\end{array}$ & $\begin{array}{l}\text { High CTDIvol (CTDIvol } \geq \mathrm{Me} \text {, } \\
\qquad \mathrm{n}=30 \text { ) }\end{array}$ & $\mathrm{p}$-value \\
\hline \multicolumn{5}{|c|}{ Aortic annulus } \\
\hline Maximum dimension & $\begin{array}{c}\text { measurement AD [mm] } \\
\text { measurement RD } \\
\text { measurement CV [\%] }\end{array}$ & $\begin{array}{l}1.33 \pm 0.76 \\
0.05 \pm 0.03 \\
3.63 \pm 2.18\end{array}$ & $\begin{array}{l}1.37 \pm 0.76 \\
0.05 \pm 0.03 \\
3.54 \pm 2.10\end{array}$ & $\begin{array}{l}0.866 \\
0.878 \\
0.878\end{array}$ \\
\hline Minimum dimension & $\begin{array}{c}\text { measurement } \mathrm{AD} \text { [mm] } \\
\text { measurement RD } \\
\text { measurement CV [\%] }\end{array}$ & $\begin{array}{l}1.17 \pm 0.91 \\
0.05 \pm 0.04 \\
3.73 \pm 2.92\end{array}$ & $\begin{array}{l}1.20 \pm 0.89 \\
0.06 \pm 0.04 \\
3.93 \pm 2.96\end{array}$ & $\begin{array}{l}0.886 \\
0.801 \\
0.801\end{array}$ \\
\hline Mean dimension & $\begin{array}{c}\text { measurement AD [mm] } \\
\text { measurement RD } \\
\text { measurement CV [\%] }\end{array}$ & $\begin{array}{l}0.88 \pm 0.52 \\
0.04 \pm 0.02 \\
2.57 \pm 1.50\end{array}$ & $\begin{array}{l}1.05 \pm 0.66 \\
0.04 \pm 0.03 \\
3.05 \pm 1.95\end{array}$ & $\begin{array}{l}0.282 \\
0.290 \\
0.290\end{array}$ \\
\hline \multicolumn{5}{|c|}{ Aortic root } \\
\hline Maximum dimension & $\begin{array}{c}\text { measurement AD [mm] } \\
\text { measurement RD } \\
\text { measurement CV [\%] }\end{array}$ & $\begin{array}{l}1.47 \pm 0.94 \\
0.05 \pm 0.03 \\
3.22 \pm 2.19\end{array}$ & $\begin{array}{l}1.40 \pm 0.93 \\
0.04 \pm 0.03 \\
2.83 \pm 1.81\end{array}$ & $\begin{array}{l}0.783 \\
0.458 \\
0.458\end{array}$ \\
\hline Minimum dimension & $\begin{array}{c}\text { measurement } \mathrm{AD} \text { [mm] } \\
\text { measurement RD } \\
\text { measurement CV [\%] }\end{array}$ & $\begin{array}{l}1.40 \pm 0.93 \\
0.05 \pm 0.03 \\
3.42 \pm 2.34\end{array}$ & $\begin{array}{l}1.23 \pm 1.14 \\
0.04 \pm 0.04 \\
2.97 \pm 2.84\end{array}$ & $\begin{array}{l}0.537 \\
0.510 \\
0.510\end{array}$ \\
\hline Mean dimension & $\begin{array}{l}\text { measurement AD [mm] } \\
\text { measurement RD } \\
\text { measurement CV [\%] }\end{array}$ & $\begin{array}{l}1.17 \pm 0.75 \\
0.04 \pm 0.03 \\
2.71 \pm 1.91\end{array}$ & $\begin{array}{l}0.92 \pm 0.62 \\
0.03 \pm 0.02 \\
2.07 \pm 1.47\end{array}$ & $\begin{array}{l}0.163 \\
0.147 \\
0.147\end{array}$ \\
\hline Height & $\begin{array}{c}\text { measurement AD [mm] } \\
\text { measurement RD } \\
\text { measurement CV [\%] }\end{array}$ & $\begin{array}{l}1.87 \pm 1.05 \\
0.09 \pm 0.05 \\
6.20 \pm 3.61\end{array}$ & $\begin{array}{l}1.63 \pm 0.96 \\
0.08 \pm 0.04 \\
5.54 \pm 3.08\end{array}$ & $\begin{array}{l}0.374 \\
0.449 \\
0.449\end{array}$ \\
\hline \multicolumn{5}{|c|}{ Distance between the coronary artery ostium and the aortic annulus } \\
\hline Left coronary artery & $\begin{array}{c}\text { measurement AD [mm] } \\
\text { measurement RD } \\
\text { measurement CV [\%] }\end{array}$ & $\begin{array}{l}1.82 \pm 0.97 \\
0.13 \pm 0.07 \\
9.10 \pm 5.11\end{array}$ & $\begin{array}{l}1.72 \pm 0.97 \\
0.13 \pm 0.08 \\
9.39 \pm 5.32\end{array}$ & $\begin{array}{l}0.691 \\
0.827 \\
0.827\end{array}$ \\
\hline Right coronary artery & $\begin{array}{c}\text { measurement AD [mm] } \\
\text { measurement RD } \\
\text { measurement CV [\%] }\end{array}$ & $\begin{array}{l}1.60 \pm 1.16 \\
0.11 \pm 0.08 \\
7.48 \pm 5.35\end{array}$ & $\begin{array}{l}1.90 \pm 1.06 \\
0.13 \pm 0.07 \\
9.10 \pm 5.04\end{array}$ & $\begin{array}{l}0.301 \\
0.234 \\
0.234\end{array}$ \\
\hline
\end{tabular}

Values are expressed as mean \pm standard deviation (SD); AD - absolute difference; CTDIvol - computed tomography dose index volume;

TAVI - transcatheter aortic valve implantation; MDCT - multidetector row computed tomography; CV - coefficient of variation; RD - relative difference. 
Table 5. Analysis of repeatability of aortic valve measurements in MDCT scans evaluating the eligibility for TAVI in subgroups identified based on median DLP

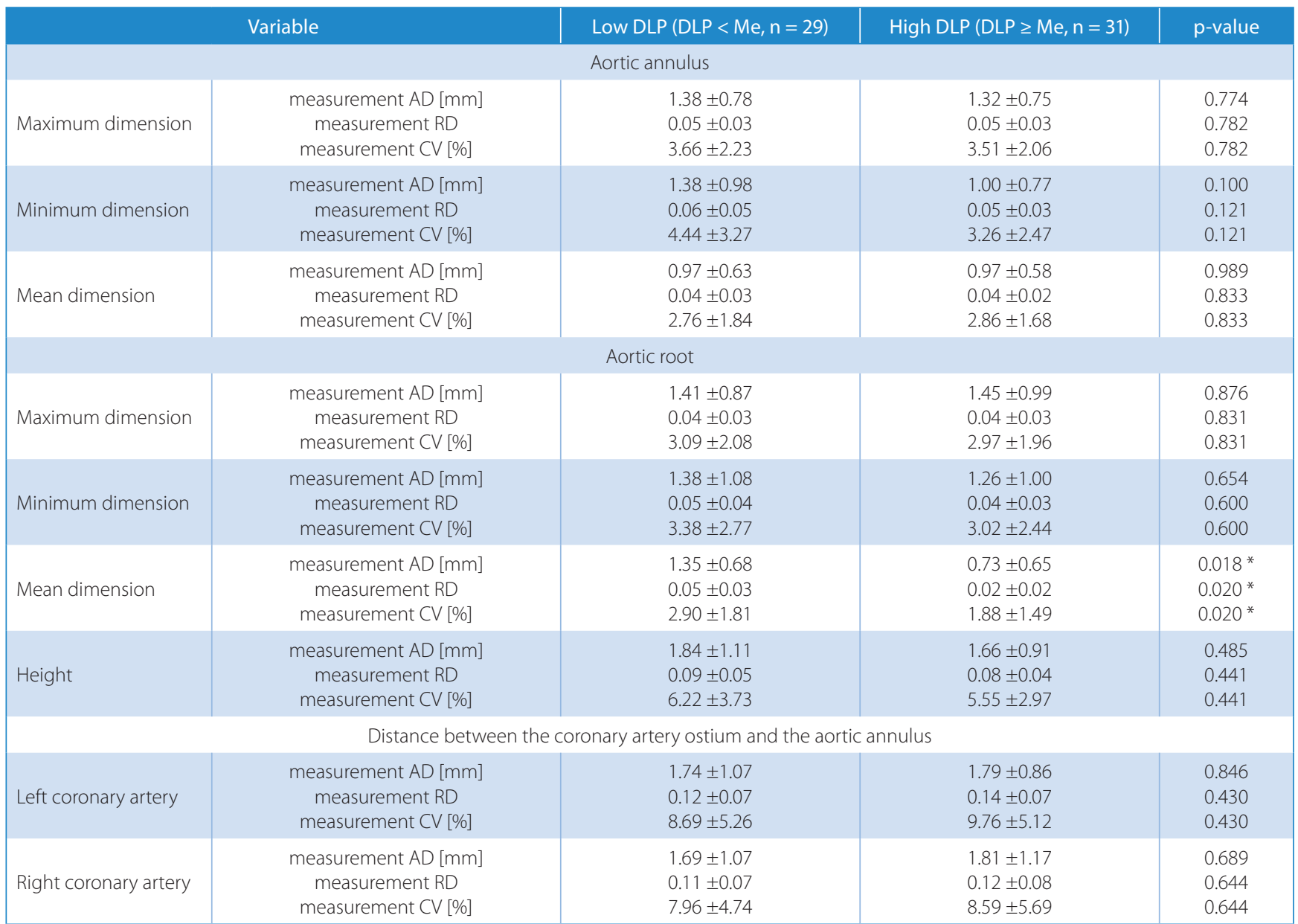

Values are expressed as mean \pm standard deviation (SD); ${ }^{*} \mathrm{p}<0.05 ; \mathrm{AD}$ - absolute difference; DLP - dose length product; CV - coefficient of variation; $\mathrm{RD}$ - relative difference; TAVI - transcatheter aortic valve implantation; MDCT - multidetector row computed tomography.

A comparative analysis of the mean values of the parameters characterizing the repeatability of various aortic valve measurements between the subgroups, based on the median DLP for the thoracic arterial phase of the MDCT examination in the assessment of eligibility for TAVI, revealed significant statistical differences regarding the measurement of the mean aortic root dimension. In the low DLP subgroup (DLP value $<$ the median), the absolute measurement difference, the relative measurement difference and the $\mathrm{CV}$ in the case of the mean dimension of the aortic valve were significantly higher than in the high DLP subgroup (DLP value $\geq$ of the median) (Table 5).

A correlation analysis of the investigated group of tests demonstrated statistically significant negative linear correlations between the DLP value in the thoracic arterial phase of the MDCT during the assessment of eligibility for TAVI, and the AD, RD and CV of the measurement of the minimum dimension of the aortic annulus $(\mathrm{r}=-0.26$, $\mathrm{r}=-0.25$ and $\mathrm{r}=-0.25$, respectively; $\mathrm{p}<0.05$ ). In addition, positive linear correlations were presented between BMI and $\mathrm{AD}, \mathrm{RD}$ and $\mathrm{CV}$ of the measurement of the minimum dimension of the aortic $\operatorname{root}(\mathrm{r}=0.28, \mathrm{r}=0.31$ and $\mathrm{r}=0.31$, respectively; $\mathrm{p}<0.05$ ), as well as between $\mathrm{BMI}$ and $\mathrm{AD}$,
$\mathrm{RD}$ and $\mathrm{CV}$ of the distance between the left coronary artery ostium and the aortic annulus $(r=0.33, r=0.28$ and $\mathrm{r}=0.28$, respectively; $\mathrm{p}<0.05)$.

A multiple stepwise forward-regression analysis determined the relationships between the basic anthropological parameters (age, sex, BMI, and BSA) or the parameters characterizing the radiation dose in the thoracic arterial phase of the MDCT examination assessing the eligibility for TAVI (CTDIvol and DLP), and the CVs for the consecutive aortic valve measurements in these tests. The conducted estimations resulted in the following statistically significant models:

- CV of the measurement of the aortic annular minimum dimension $=5.898+0.779$ female -0.001 DLP;

- CV of the measurement of the aortic root minimum dimension $=-1.789+0.206 \mathrm{BMI}+1.198$ female;

- CV of the measurement of the distance between the left coronary artery and the aortic annulus $=4.948+$ $0.394 \mathrm{BMI}+2.283$ female +0.102 age.

The models obtained in the regression analysis indicate that female sex and lower DLP doses in the thoracic arterial phase of the MDCT used to assess the eligibility for TAVI are factors independently associated with a higher $\mathrm{CV}$ for 
Table 6. Results of multiple regression analysis in the study group ( $n=60)$

A. Model of relationship determining the independent predictors of higher CV of the measurement of the aortic annular minimum dimension

\begin{tabular}{|l|c|c|c|}
\hline \multicolumn{2}{|c|}{ Model for: CV of the measurement of the aortic annular minimum dimension } \\
\hline \multicolumn{1}{|c|}{ variable } & intercept & female & 0.779 \\
\hline Regression coefficient & 5.898 & 0.362 & -0.001 \\
\hline SEM of RC & 0.989 & 0.001 \\
\hline p-value & $<0.001$ & 0.009 & 0.042 \\
\hline
\end{tabular}

DLP - dose length product; CV - coefficient of variation; SEM - standard error of the mean; Rc - regression coefficient.

B. Model of the relationship determining independent predictors of higher CV for the measurement of the aortic root minimum dimension

\begin{tabular}{|l|c|c|c|}
\hline \multicolumn{1}{|c|}{ Model for: CV of the measurement of the aortic root minimum dimension } \\
\hline \multicolumn{1}{|c|}{ variable } & intercept & BMI $\left[\mathrm{kg} / \mathrm{m}^{2}\right]$ & 0.206 \\
\hline Regression coefficient & -1.789 & 0.079 & 1.198 \\
\hline SEM of RC & 1.262 & 0.552 & 0.012 \\
\hline p-value & 0.043 & 0.041 \\
\hline
\end{tabular}

CV - coefficient of variation; SEM - standard error of the mean; Rc - regression coefficient; BMI - body mass index.

C. Model of relationship determining independent predictors of higher $\mathrm{CV}$ of the measurement of the distance between the left coronary artery ostium and the aortic annulus

\begin{tabular}{|l|c|c|c|c|}
\hline \multicolumn{4}{|c|}{ Model for: CV of the measurement of the distance between the left coronary artery ostium and the aortic annulus } \\
\hline \multicolumn{1}{|c|}{ variable } & intercept & BMI [kg/m $\left./ \mathrm{m}^{2}\right]$ & female \\
\hline Regression coefficient & 4.948 & 0.394 & 2.283 \\
\hline SEM of RC & 2.603 & 0.163 & 1.324 \\
\hline p-value & 0.046 & 0.008 & 0.102 \\
\hline
\end{tabular}

CV - coefficient of variation; SEM - standard error of the mean; RC - regression coefficient; BMI - body mass index.

the measurement of the minimum dimension of the aortic annulus. Higher BMI and female sex are independently associated with a higher $\mathrm{CV}$ for the measurement of the minimal aortic root dimension, whereas higher BMI, female sex and older age are independently associated with a higher $\mathrm{CV}$ for the measurement of the distance between the left coronary artery and the aortic annulus. The results of the estimation for significant models obtained in the regression analysis are presented in Table 6.

\section{Discussion}

In analyzing the results of this study, it is impossible to identify unequivocally a relationship between the ionizing radiation dose and repeatability of the aortic dimension measurements using MDCT performed for the standard assessment of eligibility for TAVI. The size of the radiation dose in routine MDCT tests to assess eligibility for TAVI did not affect the repeatability of the aortic valve measurements, which justifies the attempts to perform these tests using lower radiation doses. However, it is important to bear in mind the demonstrated individual statistically significant correlations, i.e., considerably higher absolute measurement difference, relative measurement difference and $\mathrm{CV}$ of the mean aortic valve diameter in the low DLP subgroup (DLP values < the median) compared to the high DLP subgroup (DLP values $\geq$ the median); statistically significant negative linear relationships between the DLP value and the absolute measurement difference, relative measurement difference and $\mathrm{CV}$ for the minimum aortic annular dimension; as well as a lower DLP dose as an independent factor associated with a higher $\mathrm{CV}$ for the minimum aortic annular dimension. Therefore, it is suggested that the MDCT tests using lower radiation doses in the assessment of eligibility for TAVI should be followed by a control of the degree of repeatability of the aortic valve sizing measurements. Based on the conducted studies, it is possible to identify groups of patients in which the variations in aortic valve sizing using MDCT may be higher. Regardless of the radiation dose, higher BMI, female sex, and elderly age affect the CV for individual measurements of the aortic valve. It seems that in these groups of patients, greater caution should be taken while performing MDCT tests using lower radiation doses in the assessment of eligibility for TAVI.

It is worth emphasizing that the presented study results are the first scientific attempt to find a relationship between the ionizing radiation dose and repeatability of aortic dimension measurements using MDCT performed for a standard assessment of eligibility for TAVI.

In the available literature, the problem of repeatability of aortic valve sizing using MDCT before a TAVI procedure was mentioned only occasionally. Schmidkonz et al. 
demonstrated that MDCT offers repeatable measurements of aortic annulus and aortic root geometry in patients eligible for TAVI. They also revealed that the highest degree of concordance was obtained for the measurements of the aortic annulus diameter estimated secondarily on the basis of the aortic annulus circumference. ${ }^{13}$ The study did not compare the repeatability of the aortic annulus circumference measurement; among the analyzed parameters, the highest concordance (the lowest CV) was obtained for the mean diameter of the aortic root.

The comparability of the aortic valve assessment was evaluated much more frequently using other diagnostic methods: echocardiography, $\mathrm{CT}$ and magnetic resonance imaging (MRI). A study by Bernhardt et al. compared the usefulness of aortic valve sizing prior to a TAVI procedure using non-contrast enhanced MRI with the gold standard, i.e., MDCT examination. In a group of 52 patients who underwent both tests, it was demonstrated that an MRI examination including a 3D steady-state freeprecession sequence covering the entire ascending aorta was highly concordant with aortic annulus assessment using MDCT. The mean aortic annular circumference in the measurement with multi-slice computed tomography (MSCT) was $76.7 \pm 6.9 \mathrm{~mm}$, whereas in the MRI test it was $76.5 \pm 6.7 \mathrm{~mm}$, with a high correlation coefficient for the measurements $(\mathrm{r}=0.93, \mathrm{p}<0.0001) .{ }^{14}$ Husser et al. compared the results of aortic valve assessments in patients eligible for TAVI which had been obtained using 3D transesophageal echocardiography (3D-TEE) with the results obtained with the use of MDCT. Based on the comparison of results in a group of 57 patients, the aortic annular diameters and surface areas assessed using 3D-TEE are clearly lower than those obtained in MSCT, with the exception of diameters measured in the sagittal planes. Only in these planes did both methods determine the final size of the prosthesis with a similar accuracy. ${ }^{15}$ Other studies by the same researchers compared the results of aortic valve sizing using 2D transesophageal echocardiography (2D-TEE) with 3D-TEE. They demonstrated that the mean aortic annulus diameters were significantly greater in 3D-TEE than in 2D-TEE, with a mean difference of $1.2 \mathrm{~mm}$. The size of the prosthetic valvular implant was correctly determined based on $67 \%$ of 2 D-TEE tests and $80 \%$ of 3D-TEE tests. Discrepancies between 2D-TEE and $3 D-T E E$ test results were observed in $26 \%$ of the analyzed cases. ${ }^{16}$ The presented study results seem to demonstrate that the use of TEE for the aortic valve sizing in patients eligible for TAVI is limited. The non-contrast enhanced MRI method is promising, but its accessibility is lower compared to MDCT, and the duration of the test is longer, which may be of key importance for patients with severe aortic stenosis. In this context, the authors believe that it is increasingly important to refine the MDCT method in the assessment of eligibility for TAVI.

In relation to the discussed parameters, the significance of the morphological type of the aortic valve should be mentioned. In the studied group of patients, 93.3\% had a tricuspid aortic valve, $5.0 \%$ had a bicuspid aortic valve and $1.7 \%$ had a quadricuspid aortic valve. The above distribution is similar to the literature data regarding the frequency of individual aortic valve types. Based on the epidemiological studies, the tricuspid aortic valve is considered to be the most common type (98-99.5\% of individuals), the bicuspid valve is found in $0.5-2 \%$ of individuals and other types are observed only occasionally. ${ }^{17}$ The bicuspid aortic valve is often associated with abnormalities, mainly with a predisposition for aortic stenosis. ${ }^{18,19}$ The distribution obtained in the presented study, including 5.0\% of patients with bicuspid valves in the group of patients diagnosed with aortic stenosis eligible for a valve replacement procedure, may be considered typical for the population.

This study has certain significant limitations, including a relatively low number of patients participating in the project, a lack of complete clinical characteristics of the patients, including cardiovascular comorbidities and risk factors, considerations related to tests performed using a single tomography scanner, a lack of tests conducted with reduced ionizing radiation doses, a lack of dose determination using size-specific dose estimate (SSDE), a lack of determination of intrapersonal repeatability of the measurements, and the subjective selection of the analyzed aortic valve dimensions. However, the authors believe that these limitations do not undermine the usefulness of the study, which may be considered in further research associated with the presented issue.

\section{Conclusions}

The size of the radiation dose in routine MDCT tests assessing eligibility for TAVI essentially does not affect the repeatability of the aortic valve measurements, which justifies the attempts to perform these tests using lower radiation doses.

Due to the demonstrated individual correlations between the radiation dose in MDCT studies performed during the assessment of eligibility for TAVI and the repeatability of aortic valve sizing, it is proposed that tests at lower radiation doses should be followed by a control of the degree of repeatability of the aortic valve sizing.

\section{ORCID iDs}

Bartłomiej Kędzierski (D) https://orcid.org/0000-0002-9109-0368 Paweł Gać (ID https://orcid.org/0000-0001-8366-0239 Martyna Głośna (D) https://orcid.org/0000-0001-9271-7401 Rafał Poręba (D) https://orcid.org/0000-0002-5109-8023 Krystyna Pawlas (D) https://orcid.org/0000-0001-5485-7649

\section{References}

1. Thaden JJ, Nkomo VT, Enriquez-Sarano M. The global burden of aortic stenosis. Prog Cardiovasc Dis. 2014;56(6):565-571.

2. Bajona P, Suri RM, Greason KL, Schaff HV. Outcomes of surgical aortic valve replacement: The benchmark for percutaneous therapies. Prog Cardiovasc Dis. 2014;56(6):619-624. 
3. Krasopoulos G, Falconieri F, Benedetto U, et al. European real world trans-catheter aortic valve implantation: Systematic review and meta-analysis of European national registries. J Cardiothorac Surg. 2016;11(1):159.

4. Davlouros PA, Mplani VC, Koniari I, Tsigkas G, Hahalis G. Transcatheter aortic valve replacement and stroke: A comprehensive review. J Geriatr Cardiol. 2018;15(1):95-104.

5. Debonnaire P, Katsanos S, Delgado V. Computed tomography to improve TAVI outcomes. Eurolntervention. 2012;8(5):531-533.

6. Achenbach S, Delgado V, Hausleiter J, Schoenhagen P, Min JK, Leipsic JA. SCCT expert consensus document on computed tomography imaging before transcatheter aortic valve implantation (TAVI)/transcatheter aortic valve replacement (TAVR). J Cardiovasc Comput Tomogr. 2012;6(6):366-380.

7. Mettler FA. Medical effects and risks of exposure to ionising radiation. J Radiol Prot. 2012;32(1):N9-N13.

8. Vano E. Global view on radiation protection in medicine. Radiat Prot Dosimetry. 2011;147(1-2):3-7.

9. Newman B, Callahan MJ. ALARA (as low as reasonably achievable) CT 2011: Executive summary. Pediatr Radiol. 2011;41(Suppl 2):453-455.

10. Cohen MD. ALARA, image gently and CT-induced cancer. Pediatr Radiol. 2015;45(4):465-470.

11. Niwa O, Barcellos-Hoff MH, Globus RK, et al. ICRP Publication 131 : Stem cell biology with respect to carcinogenesis aspects of radiological protection. Ann ICRP. 2015;44(3-4):347-357.

12. Kalra MK, Sodickson AD, Mayo-Smith WW. CT radiation: Key concepts for gentle and wise use. Radiographics. 2015;35(6):1706-1721.
13. Schmidkonz C, Marwan M, Klinghammer L, et al. Interobserver variability of CT angiography for evaluation of aortic annulus dimensions prior to transcatheter aortic valve implantation (TAVI). Eur J Radiol. 2014;83(9):1672-1678.

14. Bernhardt P, Rodewald C, Seeger J, et al. Non-contrast-enhanced magnetic resonance angiography is equal to contrast-enhanced multislice computed tomography for correct aortic sizing before transcatheter aortic valve implantation. Clin Res Cardiol. 2016;105(3): 273-278.

15. Husser $\mathrm{O}$, Holzamer A, Resch $M$, et al. Prosthesis sizing for transcatheter aortic valve implantation: Comparison of three dimensional transesophageal echocardiography with multislice computed tomography. Int J Cardiol. 2013;168(4):3431-3438.

16. Husser O, Rauch S, Endemann DH, et al. Impact of three-dimensional transesophageal echocardiography on prosthesis sizing for transcatheter aortic valve implantation. Catheter Cardiovasc Interv. 2012; 80(6):956-963.

17. Ko SM, Song MG, Hwang HK. Bicuspid aortic valve: Spectrum of imaging findings at cardiac MDCT and cardiovascular MRI. AJR Am J Roentgenol. 2012;198(1):89-97.

18. Siu SC, Silversides CK. Bicuspid aortic valve disease. J Am Coll Cardiol. 2010;55(25):2789-2800.

19. Roberts WC, Ko JM. Frequency by decades of unicuspid, bicuspid, and tricuspid aortic valves in adults having isolated aortic valve replacement for aortic stenosis, with or without associated aortic regurgitation. Circulation. 2005;111(7):920-925. 